\title{
8 Bibliografie
}

\section{Archivquellen}

Zentrales staatliches Archiv der Republik Usbekistan

(Центральный государственный архив Республики Узбекистан TsGARUz)

f. 1619 - Zentralverwaltung für Statistik (Центральное статистическое управление)

f. 2532 - Architektenunion Usbekistans (Союз архитекторов Узбекистана)

Staatliches Archiv des Gebiets von Samarkand

(Самаркандский Областной Государственный Архив Sam0GA)

f. 26 - Kommunal- und Wohnkomission des Stadtispolkoms (Жилищно-коммунальная комиссия Горисполкома)

f. 1617 - Abteilung für Bau- und Architektur des Gebietsisbolkoms (Отдел по делам строительства и архитектуры Облисполкома)

f. 1658 - Architektur- und Planungsverwaltung (Архитектурно-планировочное управление)

\section{Literatur}

\section{Abashin 2011}

Сергей Абашин 2011. 'Советская власть и узбекская махалля' in: Неприкосновенный запас 78(4), 96-110.

\section{Abashin 2015}

Сергей Абашин 2015. Советский Кишлак. Между колониализмом и модернизацией. Moskau: Новое литературное обозрение.

\section{AKTC 1996}

The Aga Khan Trust for Culture 1996 Historic Cities Support Programme. Planning for the historic City of Samarkand. Zugriff über: https://www.akdn.org/publication/aga-khanhistoric-cities-programme-planning-historic-city-samarkand-uzbekistan (letzter Zugriff am 30.06.2020).

Alexander, Buchli, Humphrey (Hg.) 2007

Catherine Alexander, Victor Buchli and Caroline Humphrey (Hg.) 2007. Urban life in postSoviet Asia, London: UCL Press.

\section{Alexandrovich / Kalinovskaya 1968}

А. Александрович, Т. Калиновская 1968. 'Об исторически сложившихся центрах городов Самараканда, Бухары и Хивы', in: Строительство и архитектура Узбекистана, 1968(10), 31-34.

Andrusz 1984

Gregory D. Andrusz 1990 (1984). Housing and Urban Development in the USSR, London: Macmillan. 


\section{Babakhanov 1960}

А. Бабаханов 1960. Малоэтажное строительство в Узбекистане, Taschkent: ФАН.

\section{Berliner 1952}

Joseph S. Berliner 1952. 'The Informal Organization of the Soviet Firm', in: The Quarterly Journal of Economics 66(3), 342-365.

\section{Biryukov 1971}

Бирюков 1971. 'Проблемы жилищного строительства', in: Ташкентская Правда, 4.02.1971.

\section{Bohn 2008}

Thomas M. Bohn 2008. Minsk - Musterstadt des Sozialismus. Stadtplanung und Urbanisierung in der Sowjetunion nach 1945, Köln/Weimar/Wien: Böhlau.

\section{Bulatov 1962}

Митхат Булатов 1962. 'Задачи градостроителей Узбекистана', in: Cmроительство и архитектура Узбекистана, 1962(01), 11-12.

\section{Buttino 2012}

Marco Buttino 2012. 'Minorities in the Urban Territory of Samarkand from the Soviet Years to the Present', in: Marco Buttino (Hg.), Changing Urban Landscapes. Eastern European and post-Soviet cities since 1989, Rom: Viella, 57-93.

\section{Buttino 2015}

Marco Buttino 2015. Samarcanda storie in una città dal 1945 a oggi, Rom: Viella.

\section{Chebotareva 1968}

Злата Чеботарева 1968. 'Опыт проектирования экспериментальных микрорайоновмахалля в Ташкенте', in: Строительство и архитектура Узбекистана, 1968(07), $11-15$.

\section{Chebotareva 1974}

Злата Чеботарева 1974. 'В защиту плотной малоэтажной застройки' in: Cmроительство и архитектура Узбекистана, 1974(11), 14-18.

\section{Chukhovich 2014}

Boris Chukhovich 2014. 'Orientalist modes of modernism in architecture: Colonial/Postcolonial/Soviet', in: P. Bornet \& S. Gorshenina (Hg.) L'orientalisme des marges. Eclairages à partir de l'Inde et de la Russie, Etudes de Lettres 2014(2-3), 263-293.

\section{Demchenko 2011}

Igor Demchenko 2011. 'Decentralized Past: Heritage Politics in Post-Stalin Central Asia', in: Future Anterior: Journal of Historic Preservation, History, Theory, and Criticism, 8(1), 65-80.

\section{DiMaio 1974}

Alfred John DiMaio, Jr. 1974. Soviet Urban Housing. Problems and policies, London: Praeger.

\section{Fedorov 2010}

Алексей Федоров 2010. 'Хроники повседневной жизни Москвича в 1917-1920 гг. Жилищный вопрос', in: Труды Института российской истории 2008(9), 39-245.

\section{Fick 1971}

Fick, K.E. 1971. ,Die Großstädte in Sowjet-Mittelasien. Entwicklung, Gestalt und Funktion der Siedlungszentren eines kontinentalen Trockenraumes', Hamburger Geographische Studien, Festschrift für Albert Kolb, 24, 159-197.

French / Hamilton (Hg.) 1979

R. Antony French \& F. E. Hamilton (Hg.) 1979. The Socialist City. Spatial structure and urban policy, Chichester et al.: John Wiley \& Sons. 


\section{French / Hamilton 1979}

R. Antony French \& F. E. Hamilton 1979. 'Is there a Socialist City?’, in: R. Antony French \& F. E. Hamilton (Hg.) The Socialist City. Spatial structure and urban policy, Chichester et al.: John Wiley \& Sons, 1-22.

Fursenko [Hg.] 2015

Александр Фурсенко (Hg.) 2015. Президиум ЦК КПСС 1954-1964, Bd. I, Черновые протокольные записи заседаний. Стенограммы. Moskau: Росспэн.

Gangler et al. 2006

Anette Gangler et al. 2006. Städte Usbekistans zwischen Tradition und Fortschritt. Städtische Transformationsprozesse der zentralasiatischen Städte Taschkent und Samarkand. Cottbus/Stuttgart.

\section{Geering 2019}

Corinne Geering 2019. Building a Common Past: World Heritage in Russia under Transformation, 1965-2000. Göttingen: V\&R unipress.

\section{Giese 1979}

Ernst Giese 1979. 'Transformation of Islamic Cities in Soviet Middle Asia into Socialist

Cities', in: R. Antony French \& F. E. Hamilton (Hg.) The Socialist City. Spatial structure and urban policy, Chichester et al.: John Wiley \& Sons, 145-165.

\section{Gordeeva 1969}

И. Гордеева 1969. 'О реконструкции городов Узбекистана', in: Cтроительство и архитектура Узбекистана, 1969(04), 24-28.

Grinevich et al. 1972

Е. Гриневич et al. 1972. 'Исследование исторической зоны Самарканда', in: Строительство и архитектура Узбекистана, 1972(07), 12-24.

\section{Gumilevskaya 2008}

0. Гумилевская 2008. 'Ответственность за самовольное строительство в России', in: Общество и право, 19(1), 98-101.

\section{Harris 2013}

Steve E. Harris 2013. Communism on Tomorrow Street. Mass housing and everyday life after Stalin, Washington / Baltimore: Woodrow Wilson Center Press / Johns Hopkins University Press.

\section{Ironside 2014}

K. Ironside 2014. 'Khrushchev's Cash-and-Goods Lotteries and the Turn Toward Positive Incentives', in: The Soviet and Post-Soviet Review, 41(3), 296-323.

\section{Josephson 1995}

Paul R. Josephson 1995. “"Projects of the Century” in Soviet History: Large-Scale Technologies from Lenin to Gorbachev', in: Technology and Culture, 36(3), 519-559.

\section{Kalinovskaya / Aleksandrovich 1972}

Т. Калиновская, А. Александрович 1972. 'О работе над генеральным планом Самарканда', in: Строительство и архитектура Узбекистана, 1972(4), 33-35.

\section{Khorev 1971}

Б. С. Хорев 1971. Проблемы городов. Экономико-географическое исследование городского расселения в СССР, Moskau: Мысль.

\section{Kontorer 1971}

P. Конторер 1971. 'Расселение многодетных семей в условиях Узбекистана', in: Строительство и архитектура Узбекистана, 1971(08), 34-38. 


\section{Kopp 1970}

A. Kopp 1970. Town and Revolution. Soviet architecture and city planning 1917-1935, New York: Thames \& Hudson.

\section{Kosenkova 2009}

Юлия Косенкова 2009. 'Советская архитектура в поисках средств создания благоприятной среды', in: Academia. Архитектура и строительство, 2009(05), 15-19.

\section{Kotkin 1997}

Stephen Kotkin 1997. Magnetic Mountain. Stalinism as a civilization, Berkeley: University of California Press.

\section{Kozenrenko 1928}

Н. Козеренко 1928. Жилищный кризис и борьба с ним. Moskau/Leningrad: Государственное Издательство.

\section{Kryukov / Notkin 1966}

К. Крюков, И. Ноткин 1966. 'Реконструкция древних городов и проблемы сохранения памятников архитектуры Узбекистана', in: Cтроительство и архитектура Узбекистана, 1966(11), 27-30.

\section{Kuznetsov 1968}

С. Кузнецов 1968. 'Судьба земли', in: Огонек 1986 (49), 7.

\section{Ledeneva 1998}

Alena Ledeneva 1998. Russia's economy of favours: Blat, networking, and informal exchange. Cambridge: Cambridge Univ. Press.

\section{Ledeneva (Hg.) 2018}

Alena Ledeneva (Hg.) 2018. The global encyclopaedia of informality, Vol.1. London: UCL press. Lubin 1984

Nancy Lubin 1984. Labour and Nationality in Soviet Central Asia. London and Basingstoke: Macmillan Press.

\section{Mantelini 2015}

Simone Mantellini 2015. 'Irrigation Systems in Samarkand', in: Helaine Selin (Hg.) Encyclopaedia of the History of Science, Technology, and Medicine in Non-Western Cultures, (Springer Science+Business Media Dordrecht 2015): 1-14 [DOI: 10.1007/978-94-0073934-5_9925-1]

\section{Meerovich 2014}

Марк Меерович 2014. 'Жилищная политика СССР как средство социального управления (1917-1941 гг.)', in: Сочиологические исследования 2014(1), 95-101.

\section{Messana 2011}

Paola Messana 2011. Soviet Communal Living. An oral history of the Kommunalka, New York: Palgrave Macmillan.

\section{Meuser (Hg.) 2012}

Philipp Meuser (Hg.) 2012. Architekturführer Usbekistan. Berlin: DOM Publishers.

\section{Mumford 2009}

Eric Mumford 2009. 'CIAM and the Communist Bloc, 1928-59', in: The Journal of Architecture, 14(2), 237-254.

\section{Muminov 1970}

Ибрагим Муминов 1970. История Самарканда, Том. 2., Taschkent: Фан.

Nazaryan 2007

Рубен Назарян 2007. Армяне Самаранда, Moskau: Bec. 


\section{Nil'sen 1988}

Владимир Нильсен 1988. У истоков современного градостроительства Узбекистана. XIX - начало XX веков. Taschkent: Гафур Гулям.

\section{Notkin / Gordeeva 1972}

И. Ноткин, И. Гордеева 1972. 'Памятники архитектуры и реконструкция городов Узбекистана', in: : Строительство и архитектура Узбекистана, 1972 (07), 7-11.

\section{Pugachenkova 1973}

Галина Пугаченкова 1973. 'Вклад ученых Узбекистана в изучение архитектурного наследия республики', in: Строительство и архитектура узбекистана, 1973 (07), 1-3.

\section{Pulatov 1971}

Х. Пулатов 1971. 'Планировочная структура народного жилья Ташкентской области', in: Строительство и архитектура Узбекистана, 1971(09), 17-19.

\section{Ramm / Viertelhaus 2016}

Henning Hraban Ramm, Benedikt Viertelhaus (Hg.) 2016. Architekturführer Bischkek. Berlin: DOM Publishers.

\section{Razykov 1958}

А. Разыков 1958. 'Индивидуальному строительству жилья повседневное внимание', in: Блокнот агитатора (Ташкент), 1958(3), 11-18.

\section{Rusanova 1968}

Л. Русанова 1968. 'Демография и жилище. По материалам исследования Самарканда', in: Строительство и архитектура Узбекистана, 1968(03), 28-30.

\section{Rywkin 1980}

Michael Rywkin 1980. 'Housing in Central Asia: The Uzbek Example’, in: Steven A. Grant (Hg.) Soviet Housing and Urban design, Washington: U.S. Dept. of Housing and Urban Development, 39-42.

\section{Schlager 2017}

Edda Schlager 2017. Architekturführer Duschanbe. Berlin: DOM Publishers.

\section{Sgibnew 2015}

Wladimir Sgibnev 2015. 'Remont: housing adaption as meaningful practice of space production in post-Soviet Tajikistan', in: Europa regional / Modernism and the (post-)socialist city, 22.2014 (1-2), 53-64.

\section{Shakirov 1971}

О. Шакиров 1971. 'Об итогах конкурса на проект планировки и застройки Самарканда', in: Строительство и архитектура узбекистана, 1971(07), 18-20.

\section{Smith 2008}

Mark B. Smith 2008. 'Individual Forms of Ownership in the Urban Housing Fund of the USSR, 1944-64', in: The Slavonic and East European Review 86(2), 283-305.

\section{Smith 2010}

Mark B. Smith 2010. Property of Communists. The urban housing program from Stalin to Khrushchev, DeKalb: Northern Illinois University Press.

\section{Stadelbauer 1994}

Jörg Stadelbauer 1994. ,Das Ende der „Sozialistischen Stadt“? Zu einigen Transformationsansätzen in russischen Großstädten', in: M. Domrös \& Klaer W. (Hg.) Festschrift für Erdmann Gormsen zum 65. Geburtstag, Mainz: Geographisches Institut der Johannes Gutenberg-Universität, 179-196. 


\section{Stronski 2010}

Paul Stronski 2010. Tashkent. Forging a Soviet City. 1930-1966, Pittsburgh: University of Pittsburgh Press.

\section{Sukhanov 1972}

И. Суханов 1972. 'Состояние и задачи архитектурной климатологии в Узбекистане', in: Строительство и архитектура Узбекистана, 1972(05), 21-24.

\section{Sulkevich 1940}

С. И. Сулкевич 1940. Территория и население СCCP, Moskau: Политиздат.

\section{Tokhtiev 2012}

Ш. Тохтиев 2012. 'Краткая история Самаркандских и Бухарских «Ирани»', in: Вестник Челябинского государствоенного университета, 33(287), 124-129.

\section{Trevisani 2010}

Tommaso Trevisani 2010. Land and power in Khoresm: Farmers Communities and the State in Uzbekistan's Decollectivisation, Wien: Lit

\section{Vereshchak 2011}

Светлана Верещак 2011. 'Становление правового регулирования жилищных прав граждан в период НЭПа (1921-1929 гг.)', in: Пробелы в российском законодательстве. Юридический журнал, 2011(4), 207-210.

\section{Voronina 1951}

В. Воронина 1951. Народные традиции архитектуры Узбекистана. Moskau: Государственное издательство архитектуры и градостроительства.

\section{Williams 2001}

Brain Glyn Williams 2001. The Crimean Tatars. The diaspora experience and the forging of a nation, Leiden (et al.): Brill.

\section{Wirth 2002}

Eugen Wirth 2002. Die orientalische Stadt im islamischen Vorderasien und Nordafrika: städtische Bausubstanz und räumliche Ordnung, Wirtschaftsleben und soziale Organisation, Mainz: von Zabern.

\section{Zhilina 1978}

А. Жилина 1978. 'Жилище и семья у узбеков (на материалах Ташкентской и Хорезмской областей)', in: Снесарев (Hg.) Семья и семейные обряды у народов Средней Азии и Казахстана, Moskau: Наука, 55-93.

\section{Zhiromskaya 1992}

В.Б. Жиромская 1992. 'Всесоюзная перепись населения 1939 г. История проведения, оценка достоверности', in: Поляков Юрий Александрович (Hg.) Всесоюзная перепись населения 1939 года. Основные итоги, Moskau.: Наука, 4-12.

\section{Gesetzestexte}

\section{Dekret über den Boden vom 28.10.1917}

'Декрет о Земле. ІІ Съезд Советов рабочих и солдатских депутатов.' in Известия, 28. Oktober 1917.

\section{Verfassung der Sowjetuinion von 1936}

Конституция. Основной Закон Союза Советских Социалистических Республик. 1936 http://doc.histrf.ru/20/konstitutsiya-sssr-1936-goda/ (letzter Zugriff am 30.06.2020). 
Erlass des Exekutivkomitees des SNK vom 17.10.1937

Постановление ЦИК, СНК СССР от 17.10.1937 'О сохранении жилищного фонда и улучшении жилищного хозяйства в городах', in: Центральный Исполнительный Комитет СССР N 112 Совет Народных Комиссаров СССР. Постановление N 1843 от 17 октября 1937 года. http://www.libussr.ru/doc_ussr/ussr_4124.htm (letzter Zugriff am 30.06.2020).

\section{Erlass des SNK 1940 vom 22.05.1940}

Постановление СНК от 22.05.1940 'О мерах борьбы с самовольным строительством в городах, рабочих, курортных и дачных поселках.' http://www.libussr.ru/ doc_ussr/ussr_4245.htm (letzter Zugriff am 30.06.2020).

\section{Erlass des SNK vom 29.05.1944}

Постановление от 29 мая 1944 г. N 625 'О мероприятих по восстановлению индивидуального жилищного фонда в освобожденных районах и усилению индивидуального жилищного строительства в городах и рабочих поселках СССР.' https://econ.wikireading.ru/78761 (letzter Zugriff am 30.06.2020).

\section{Verordnung des Präsidiums des Obersten Rates der UdSSR vom 26.08.1948}

Указ Президиума Верховного Совета СССР от 26.08.1948 'O праве граждан на покупку и строительство индивидуальных жилых домов'

http://www.libussr.ru/doc_ussr/ussr_4711.htm (letzter Zugriff am 30.06.2020).

\section{Erlass des ZK der KPdSU vom 04.11.1955}

Постановление ЦК КПСС, Совмина СССР от 04.11.1955 'Об устранении излишеств в проектировании и строительстве'. http://www.libussr.ru/doc_ussr/ussr_5043.htm (letzter Zugriff am 30.06.2020).

\section{Erlass des Zentralkomitees und Ministerrates der UdSSR vom 31.07.1957}

„Über die Entwicklung des Wohnungsbaus in der UdSSR“

Постановление цК КПСС и Совмина СССР от 31.07.1957 'О развитии жилищного строительства в СССР'. http://www.libussr.ru/doc_ussr/ussr_5213.htm (letzter Zugriff am 30.06.2020).

\section{Vedomosti Verchovnogo Soveta UzSSR 1960 N. 26 S. 31-32}

Ведомости Веховоного Совета УзССР 1960 N. 26 S. 31-32. 'Об ответственности граждан за самовольное строительство в городах'.

\section{Strafgesetzbuch RSFSR 1960}

Уголовный кодекс РСФСР 1960

https://lawrussia.ru/bigtexts/law_3558/index.htm (letzter Zugriff am 30.06.2020).

\section{Programm der KPdSU von 1961}

'Программа Коммунистической Партии Советского Союза. Принята XXII съездом КПСС' http://leftinmsu.narod.ru/polit_files/books/III_program_KPSS_files/III_program_KPSS.htm (letzter Zugriff am 30.06.2020). 


\section{Byulleten' Verchovnogo Suda SSSR 1962}

Бюллетень Верховного Суда СССР /

Постановление Пленума Верховного Суда СССР от 31 июля 1962 г. № 13 'О судебной практике по делам о праве личной собственности на строения', S. 24 Punkt 10.

\section{Erlass des ZK der KPdSU vom 01.06.1962}

Постановление ЦК КПСС, Совмина СССР от 01.06.1962 N 561 'Об индивидуальном и кооперативном жилищном строительстве'. http://pravo.levonevsky.org/baza/ soviet/sssr5798.htm (letzter Zugriff am 30.06.2020).

\section{Erlass des Ministerrates der RSFSR vom 03.09.1963}

Постановление Совета Министров РСФСР от 03.09.1963 'О ходе выполнения плана кооперативного жилищного строительства в РСФСР в 1963 году'. http://www.libussr.ru/doc_ussr/usr_5991.htm (letzter Zugriff am 30.06.2020).

\section{Gesetz der UdSSR Nr. 3401-VII vom 13.12.1968}

Закон СССР от 13.12.1968 N 3401-VII 'Об утверждении основ земельного законодательства союза ССР и союзных республик'. http://www.libussr.ru/doc_ussr/usr_6955.htm (letzter Zugriff am 30.06.2020).

\section{Internetquellen}

\section{Kosenkova 'Gradostroitel'noe myshlenie'}

Юлия Косенкова, Градостроительное мышление советской эпохи: поиск устойчивых структур http://www.alyoshin.ru/Files/publika/kosenkova/kosenkova_mish.html (letzter Zugriff am 30.06.2020).

\section{Offizielle Webseite der Stadt Samarkand}

https://samarkand.uz/towns_districts/samarkand (letzter Zugriff am 30.06.2020).

\section{Sammlung der Volkszählungen der Sowjetischen und Russischen Geschichte} bei demoscope.ru http://www.demoscope.ru/weekly/ssp/census.php (letzter Zugriff am 30.06.2020 
